\title{
Heartbeat: Managing cardiovascular disease as a family of diseases in the community
}

doi:10.1136/heartjnl-2017-311713

Although at least $80 \%$ of cardiovascular disease (CVD) is potentially preventable by the elimination of health risk behaviours, implementation of effective, large scale and sustainable CVD prevention programs is still a challenge. In this issue of Heart, Connolly et al ${ }^{1}$ describe an experience in which patients at high risk of or with established CVD underwent a 12 week community-based nurse-led prevention programme called My Action (figure 1) which included lifestyle and risk factor management, prescription of medication and weekly exercise and education sessions. The programme is in accordance to recent British recommendations that CVD should be managed as a family of diseases in the community. The study was conducted in Westminster, a culturally and socioeconomically diverse borough in central London. Over a 6 year period, 3232 patients attended an initial assessment, $63 \%$ were male and $48 \%$ belonged to black and minority ethnic groups; $56 \%$ attended an end of programme assessment and $33 \%$ a 1 year assessment. The results were very encouraging in both high risk and CVD patients, with improvement in goals related to unhealthy habits and increase in proportions of patients achieving their BP (CVD +15.4\%; highrisk $+25 \%)$ and LDL-cholesterol targets (CVD $+6 \%$, high-risk $+23 \%)$, as well increase of use of statins and antihypertensive medications in high-risk subjects and improvements in depression scores and quality of life measures. Most improvements were maintained after 1 year.

In the companion editorial, Dr Ofori ${ }^{2}$ discusses the key principles of a modern integrated preventive cardiology programme (table 1), saying that 'a paradigm shift from provider- or disease-centred care to person-centred care is required'. For Dr. Ofori, the MyAction, a nurse-led multidisciplinary prevention programme, exemplifies the

\footnotetext{
${ }^{1}$ University Hospital and School of Medicine, Universidade Federal de Minas Gerais, Brazil ${ }^{2}$ University of Washington School of Medicine, Seattle, USA
}

Correspondence to Professor Catherine M Otto, University of Washington School of Medicine, Seattle, USA; cmotto@uw.edu

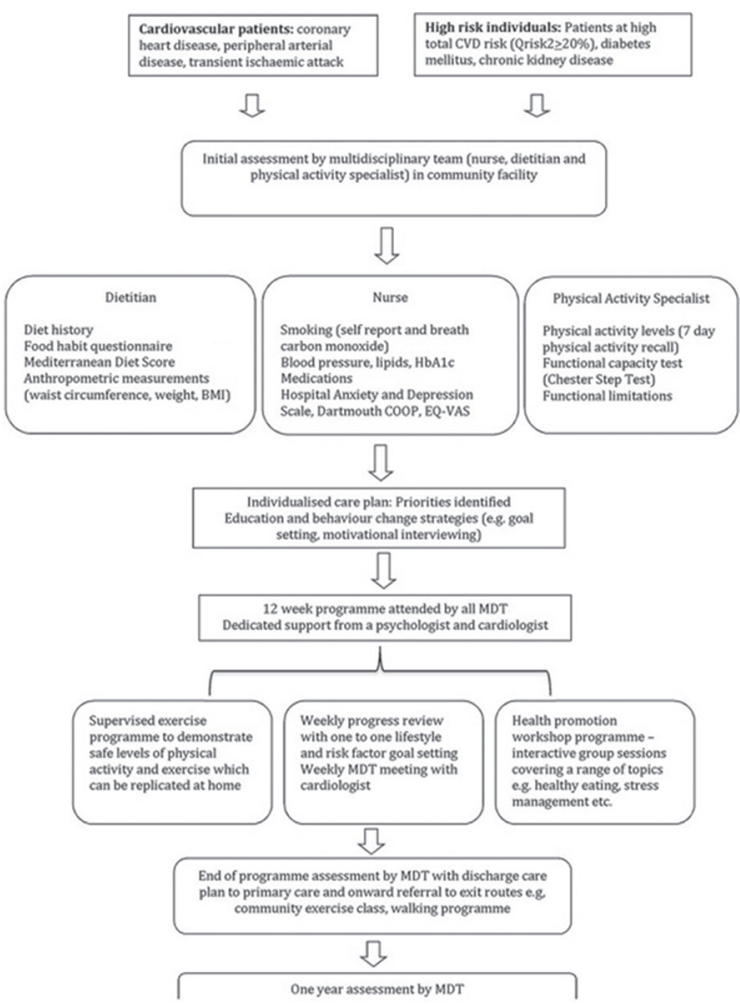

Figure 1 The MyAction prevention programme. ${ }^{1}$

future direction of modern preventive cardiology and a viable way to realise the aims of reducing CVD events.

\begin{tabular}{ll}
\hline Table 1 Key principles of a modern integrated preventive cardiology programme \\
\hline Principle & Aim \\
\hline Inclusive preventive care & $\begin{array}{l}\text { Should target all individuals at risk for new or recurrent CVD. } \\
\text { Integrated across the continuum of care from CR and secondary care centres and } \\
\text { general practices. }\end{array}$ \\
\hline Equity of access & $\begin{array}{l}\text { To promote higher rates of participation and adherence by having the service in } \\
\text { the communities where people live and work. } \\
\text { This aids in reducing inequalities. }\end{array}$ \\
\hline Family-centred programme & $\begin{array}{l}\text { Presents an opportunity to reach first-degree relatives of people with premature } \\
\text { CVD. }\end{array}$ \\
& $\begin{array}{l}\text { Family members share the same lifestyle risk factors, and positive changes will be } \\
\text { more long -lasting when the whole family is involved. }\end{array}$ \\
\hline $\begin{array}{l}\text { Nurse-led multidisciplinary } \\
\text { programme }\end{array}$ & $\begin{array}{l}\text { Nurse-led/coordinated programmes have been shown to be effective in CVD risk } \\
\text { reduction. } \\
\text { The programme should be } \\
\text { provided without specialised } \\
\text { hospital facilities. }\end{array}$ \\
$\begin{array}{l}\text { This is to ensure easy replication of programme activities at home to enable } \\
\text { individuals sustain the physical activity recommendation to increase their physical } \\
\text { fitness. In addition, it ensures that this model can be applied in any setting } \\
\text { enhancing the scalability. }\end{array}$ \\
\hline Address total CVD risk & $\begin{array}{l}\text { In keeping with current CVD prevention guidelines, the total absolute CVD risk of } \\
\text { an individual is taken into consideration not just single risk factors. }\end{array}$ \\
\hline
\end{tabular}

Management of anticoagulation for prevention of embolic events in patients with atrial fibrillation (AF) and chronic 


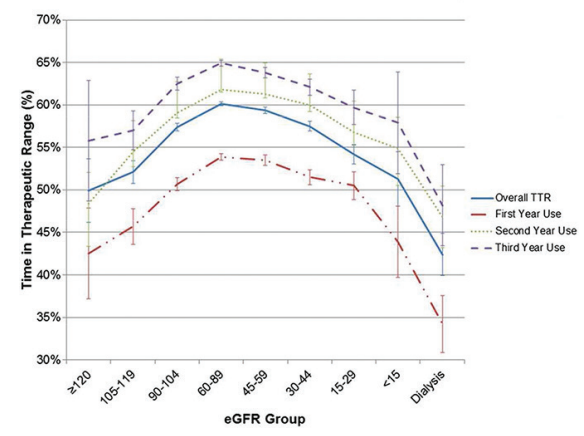

Figure 2 Percent time in therapeutic international normalised ratio (INR) range, stratified by year of warfarin use. ${ }^{3}$

kidney disease (CKD) is especially challenging. In a retrospective analysis of almost 124 thousand patients with newly diagnosed $\mathrm{AF}$, there was an inverse relationship between CKD severity and use of vitamin $\mathrm{K}$ antagonist anticoagulation. ${ }^{3}$ In addition, the time in therapeutic range was lower in those with more severe CKD; only $21 \%$ of patients on dialysis were in therapeutic range at least $60 \%$ of the time. (figure 2) The authors suggest that the variability in using Vitamin $\mathrm{K}$ antagonist therapy in CKD patients has implications for consideration of alternative therapeutic approaches in this patient population.

In an editorial, Black-Maier and Piccini ${ }^{4}$ remind us that about $20 \%$ of patients with end-stage renal disease have $\mathrm{AF}$ and an even higher risk of stroke than predicted by conventional risk factors. Management is complicated by 'alterations in haemostasis that predispose patients to haemorrhagic (platelet $\alpha$ granule depletion, reduced endothelial cell adhesion molecule expression) and thrombotic (increased circulating fibrinogen) complications, limiting extrapolation of data from patients with normal renal function.' They then discuss the potential options

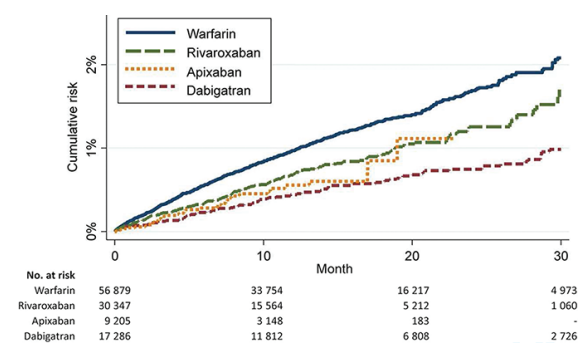

Figure 3 Cumulative risk of liver injury hospitalisation by type of oral anticoagulant, MarketScan databases, 2011-2014. Follow-up truncated at 30 months. $^{5}$ of direct oral anticoagulants (DOACs) in patients with mild to moderate CKD or left atrial appendage occlusion in dialysis patients but caution that currently there are no ideal options.

A different clinical concern in prevention of embolic events in adults with atrial fibrillation is the potential risk of liver injury with DOACs. In a database analysis of almost 114 thousand patients with atrial fibrillation with a median follow-up of 12 months, there were 960 hospitalisation for liver injury. ${ }^{5}$ The estimated rates of liver injury per 1000 personyears ranged from 4.0 with dabigatran to 9.0 with warfarin. After multivariable adjustment, hospitalisation rates for liver injury compared with warfarin were 0.57 (0.46 to 0.71$)$ for dabigatran, $0.88(0.75$ to 1.03$)$ for rivaroxaban and $0.70(0.50$ to 0.97 ) for apixaban. (figure 3) Clinical factors that increased the risk of liver injury included prior liver, gallbladder or kidney disease, cancer, anaemia, heart failure and alcoholism.

Potpara and Lip $^{6}$ put this data in context in their commentary on drug-induced liver injury (DILI) which has been reported with over 1000 medications or herbal products and has an estimated annual incidence of $1-1.5$ per 1000 to 10000 exposed people but accounts for about $10 \%$ of all acute hepatitis cases. Clinical trials are unlikely to detect rare events, such as liver injury, so these complications more often are evidence on meta-analyses or large post-market databases, such as the one reported in this issue of Heart. They go on to provide specific clinical guidance on choice of anticoagulation medications in adults with concurrent liver disease. They conclude: 'Clinical vigilance and regular follow-up of NOACs users are needed to prevent severe, potentially deleterious DILI, but there is no compelling evidence that any particular NOAC should be denied to most patients with $\mathrm{AF}$ at risk of stroke only to avoid a rare event such as DILI. However, more data are needed to inform optimal use of NOACs in patients with AF with liver dysfunction.'

The Education in Heart article in this issue, summarises the data on optimal duration of dual antiplatelet therapy after coronary stenting for an acute coronary syndrome and provide a simple proposed algorithm (figure 4).

A state-of-the-art review article by Sperry and Tang $^{8}$ discusses the genetics of amyloid heart disease. Amyloid heart disease offers a clinical model in which gene therapy with small interfering RNA and antisense oligonucleotides might stop

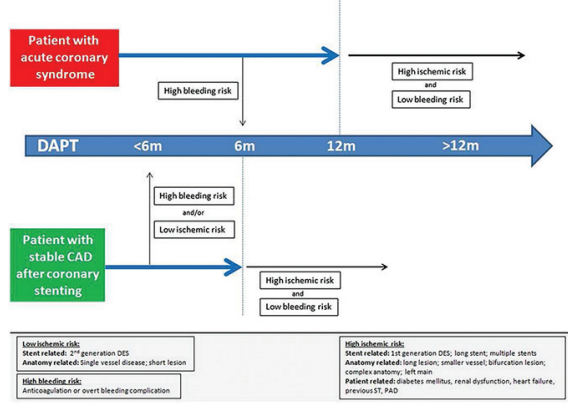

Figure 4 Proposed algorithm for optimal duration of DAPT. CAD, coronary artery disease; $D E S$, drug-eluting stent; $P A D$, peripheral artery disease; ST, stent thrombosis; DAPT, dual antiplatelet therapy. ${ }^{7}$

the abnormal protein production that leads to clinical cardiac dysfunction.

\section{Competing interests None declared.}

Provenance and peer review Commissioned; internally peer reviewed.

(c) Article author(s) (or their employer(s) unless otherwise stated in the text of the article) 2017. All rights reserved. No commercial use is permitted unless otherwise expressly granted.

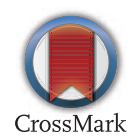

To cite Ribeiro AL, Otto CM. Heart 2017;103:803-804.

Heart 2017;103:803-804.

doi:10.1136/heartjnl-2017-311713

\section{REFERENCES}

1 Connolly SB, Kotseva K, Jennings C, et al. Outcomes of an integrated community-based nurse-led cardiovascular disease prevention programme. Heart 2017; 103:840-47.

2 Ofori SN. Integrated programmes for cardiovascular disease risk reduction: the need for new models of care. Heart 2017;103:805-6.

3 Yang F, Hellyer JA, Than C, et al. Warfarin utilisation and anticoagulation control in patients with atrial fibrillation and chronic kidney disease. Heart 2017;103:818-26.

4 Black-Maier E, Piccini JP. Oral anticoagulation in end-stage renal disease and atrial fibrillation: is it time to just say no to drugs? Heart 2017;103:807-8.

5 Alonso A, MacLehose RF, Chen LY, et al. Prospective study of oral anticoagulants and risk of liver injury in patients with atrial fibrillation. Heart 2017:103:834-9.

6 Potpara TS, Lip GY. Drug-induced liver injury with oral anticoagulants: a threat or not? Heart 2017; 103:809-11.

7 Eisen A, Bhatt DL. Optimal duration of dual antiplatelet therapy after acute coronary syndromes and coronary stenting. Heart 2017:103:871-84

8 Sperry BW, Tang WH. Amyloid heart disease: genetics translated into disease-modifying therapy. Heart 2017;103:812-7. 